\title{
Artificial Enamel Wear after Prolonged Chewing Simulation against Monolithic Y-TZP Crowns
}

\author{
Deborah Vedana1, Leonardo Vedana1, Emerson Alves Martins ${ }^{2,3}$, Peter Brodersen², \\ Grace M. De Souza ${ }^{3}$ \\ ${ }^{1}$ Prosthodontics Department, University of Vale do Itajai, Itajai, Brazil \\ ${ }^{2}$ Department of Chemical Engineering and Applied Chemistry, Faculty of Applied Science \& Engineering, University of Toronto, \\ Toronto, Canada \\ ${ }^{3}$ Faculty of Dentistry, University of Toronto, Toronto, Canada \\ Email: dlameira@yahoo.com.br
}

How to cite this paper: Vedana, D., Vedana, L., Martins, E.A., Brodersen, P. and De Souza, G.M. (2018) Artificial Enamel Wear after Prolonged Chewing Simulation against Monolithic Y-TZP Crowns. Materials Sciences and Applications, 9, 381-392. https://doi.org/10.4236/msa.2018.94026

Received: February 15, 2018

Accepted: April 15, 2018

Published: April 18, 2018

Copyright $\odot 2018$ by authors and Scientific Research Publishing Inc. This work is licensed under the Creative Commons Attribution International License (CC BY 4.0).

http://creativecommons.org/licenses/by/4.0/

\begin{abstract}
The aim of this study was to evaluate the effect of chewing simulation on wear of artificial enamel abraded against zirconia-based crowns. Fifteen crown preparations were scanned for the manufacturing of crowns using computer-aided-design/computer-aided-machining technique (CAD/CAM), according to the following $(n=5)$ : Polished (PM) and glazed (GM) monolithic zirconia (1.5 mm uniform thickness), and Bilayer (BL - $0.8 \mathrm{~mm}$ zirconia coping, $0.7 \mathrm{~mm}$ porcelain veneer) crowns. The samples were cemented and chewing simulation $\left(2.5\right.$ million cycles $/ 0-80 \mathrm{~N} /$ artificial saliva $\left./ 37^{\circ} \mathrm{C}\right)$ was performed with steatite indenters ( $6 \mathrm{~mm}$ diameter) as antagonists. Assuming the uniformity of the unaged samples, antagonists were scanned using a surface profilometer and the material loss volume was calculated. Roughness of the crowns' occlusal surface was also analyzed using the profilometer. Scanning electron microscopy was used to characterize the abraded surface. One-way ANOVA and Tukey test $(p=0.05)$ were employed for analysis of wear results. A significant difference was observed among the groups $(p<0.001)$. Artificial enamel abraded against porcelain (BL) had significantly higher material loss $\left(0.217 \mathrm{~mm}^{3} \pm 0.015\right)$ than those abraded against monolithic zirconia, polished $\left(\mathrm{PM}-0.167 \mathrm{~mm}^{3} \pm 0.02\right)$ and glazed $\left(0.101 \mathrm{~mm}^{3} \pm 0.03\right)$, which were similar to each other. Veneering porcelain results in more pronounced wear of the artificial enamel than monolithic zirconia. However, mastication against monolithic Y-TZP also imposes wear to the opposing teeth.
\end{abstract}

\section{Keywords}

Tooth Wear, Ceramics, Tooth Abrasion, Dental Porcelain 


\section{Introduction}

All-ceramic systems have been used as an esthetic alternative to porcelain-fused-to-metal (PFM) crowns and fixed partial dentures (FPD). In particular, zirconia ceramics present superior mechanical properties than the other systems, due to its high flexural strength of $900-1400 \mathrm{MPa}$ [1], that allows for the manufacturing of FPDs in high masticatory load areas. Zirconia presents three different crystalline configurations depending on the temperature range: Monoclinic, from room temperature to $1170^{\circ} \mathrm{C}$; tetragonal, from $1170^{\circ} \mathrm{C}$ to $2370^{\circ} \mathrm{C}$; and cubic, at temperatures above $2370^{\circ} \mathrm{C}$. The tetragonal phase is related to the strongest mechanical properties of zirconia [2] and therefore needs to be stabilized at room temperature. When cooling after sintering, zirconia undergoes volume expansion of $3 \%$ to $5 \%$, which is related to the transition from tetragonal to monoclinic phase. The stabilization of tetragonal zirconia at room temperature depends on the addition of oxides such as calcium $(\mathrm{CaO})$, magnesium $(\mathrm{MgO})$, Yttrium $\left(\mathrm{Y}_{2} \mathrm{O}_{3}\right)$ or Ceria $\left(\mathrm{CeO}_{2}\right)$ [3]. Yttria-tetragonal zirconia polycrystal (Y-TZP) is a zirconia-based ceramic stabilized with $3 \mathrm{~mol} \%$ yttria.

The bond strength between Y-TZP framework and veneering porcelain has been reported to be lower than that between metal framework and veneering material [4]. This leads to chipping or cracking of the porcelain veneer being the most common failure of Y-TZP veneered restorations [5]. Clinical reports indicate survival rates ranging between 79 and $100 \%$ for zirconia veneered restorations after 5 years [6] [7], and in vitro studies reported lower load-bearing capacity of the bi-layer crowns veneered in powder build-up technique [8]. Hence, a bilayer system with a strong and tough Y-TZP framework veneered with an esthetic but weak porcelain tends to fail prematurely. Failures in zirconia-veneered restorations can be circumvent by replacing the veneer/core bilayer with a monolithic restorative system [9], leading to a homogeneous load distribution throughout the entire restoration. For instance, in vitro studies showed that zirconia in bilayer configuration had significantly lower fracture strength than monolithic Y-TZP crowns [10]. The results of this in vitro study demonstrated that monolithic Y-TZP crowns might have reliable fracture strength after 5 years of occlusal loading [10].

The mechanical stability of zirconia monolithic restorations can increase the range of indications of those prostheses, however, the impact of zirconia mastication against natural teeth has not yet been fully clarified. There is a concern about the metastability of the tetragonal phase in the oral environment because Y-TZP metastable nature can lead to an unfavorable phenomenon that is known as "low temperature degradation" (LTD) [11]. This aging process can occur through an uncontrolled slow transformation of superficial grains from tetragonal-to-monoclinic phase in contact with water. Consequently there is an increase in surface roughness and micro-cracks that enable water penetration, causing further phase transformation and consequent loss of mechanical strength [11]. Previous studies have reported that zirconia causes less wear to 
opposing teeth than veneer porcelain, after artificial aging [12] [13]. However, there is a large variation between number of cycles and the vertical loading applied in these studies. Therefore, it's important to evaluate zirconia after prolonged chewing simulation to estimate the oral environment effect on its surface and the effect of Y-TZP-based restorations on tooth structure.

Even though Y-TZP monolithic crowns can be a reliable alternative to circumvent chipping susceptibility, the effect of the occlusion between zirconia and tooth structure on the roughness of zirconia and the subsequent wear of dental enamel is not known. Therefore, the aim of this study was to evaluate the effect of zirconia-based crowns on wear of artificial enamel after clinically significant aging time. The null hypothesis was that zirconia crown design, monolithic or bilayer had no effect on enamel wear after aging.

\section{Materials and Methods}

\subsection{Specimens' Preparation}

For this study, fifteen healthy bovine incisors were used, and standardized crown preparation was performed over them in a lathe machine (MAGNUM-CUT; FEL-2680 GZJ, SP, Brazil) with the following dimensions: $4.2 \mathrm{~mm}$ diameter occlusal base, $6.0 \mathrm{~mm}$ diameter cervical base and $7.0 \mathrm{~mm}$ axial height [10]. The taper angle was set at 8 degrees for all axial walls and the cervical finish line was a rounded shoulder. All preparation inner angles were rounded with fine grain diamond burs (KG Sorensen).

The specimens were randomly distributed in three groups $(\mathrm{n}=5)$ according to the crown fabrication technique: PM group: polished monolithic zirconia crowns (1.5 mm thickness); GM group: glazed monolithic zirconia crowns (1.5 $\mathrm{mm}$ thickness); BL group: zirconia copings with hand-layered porcelain veneering ( $0.8 \mathrm{~mm}$ core and $0.7 \mathrm{~mm}$ porcelain thickness).

The preparations were scanned by a non-contact optical 3D-scanning device for non-anatomical crowns manufacturing (Lava Scan system scanner; $3 \mathrm{M}$ ESPE, St. Paul, MN, USA). All zirconia crowns/copings were designed by the same technician with Lava Scan Design System. Then, zirconia blocks (Lava Plus for monolithic crowns, and Lava Frame for by-layer crowns, $3 \mathrm{M}$ ESPE) were milled by using Lava CNC 500 Milling Machine (3M ESPE, St. Paul, MN, USA). After the milling procedure, all the copings/crowns were immersed in a shade liquid for 2 minutes, and then sintered in a furnace (Lava Furnace 200) following manufacturer's instructions.

Crowns were finalized according to the experimental group as follows:

Polished monolithic (PM): crowns were finished and polished with diamond wheels and bristle brushes (Brasseler, Dental instruments, USA) until visual inspection indicated no signs of marks and scratches on the surface.

Glazed monolithic (GM): After the final sintering, crowns received a glaze firing at $720^{\circ} \mathrm{C}$ approximately and no further procedures were carried out.

Bilayer crowns (BL): Copings were veneered with the powder build-up tech- 
nique on the corresponding coping using Lava Ceram veneer ceramic (3M ESPE, St. Paul, MN, USA). The final veneered crown contour was verified by measuring it at different locations with a digital caliper, and the firing cycle was controlled by an experienced dental technician to ensure standardized crowns.

All the crowns were cleaned for $10 \mathrm{~min}$ in an ultrasonic bath (Bransonic Ultrasonic Cleaner 3510 E-DTH; Branson, Danbury, CT, USA), and cemented on their respective prepared tooth with a self-adhesive luting resin (RelyX Unicem 2; $3 \mathrm{M}$ ESPE). The cemented crowns were stabilized by applying a $5 \mathrm{Kg}$ static load for $7 \mathrm{~min}$ to allow for the resin cement to set before immersion in distilled water $\left(37^{\circ} \mathrm{C}\right)$.

\subsection{Specimens Aging}

After 24 hours immersed in distilled water, specimens were submitted to chewing simulation: $2,500,000$ cycles, $80 \mathrm{~N}$, at $37^{\circ} \mathrm{C}$ under artificial saliva bath [14]. Loading was applied with a vertical displacement of $0.2 \mathrm{~mm}$ and horizontal (occlusal) displacement of $0.5 \mathrm{~mm}$ in a chewing simulator CS-4 (SD Mechatronik, Feldkirchen-Westerham, DE). As a substitute for human enamel, hydroxyapatite steatite indenters (6 $\mathrm{mm}$ diameter) were used as antagonists and were replaced for each specimen [12].

\subsection{Material Loss and Roughness Measurement}

Unaged steatite indenters were scanned using a surface profilometer (Alpha-Step D-600, KLA Tencor Corp, CA, USA) as control samples. After chewing simulation, the aged steatite indenters were also scanned and, assuming the uniformity of control samples. The volumetric material loss was calculated based on the height and diameter of the worn surface, superimposing the three-dimensional surfaces before and after the wear test (Figure 1) [12] [15]. The occlusal surface roughness $(\mathrm{Ra})$ of the crowns was also investigated using the profilometer before and after chewing simulation. As the surfaces of the specimens were assumed to be homogenous an area in the middle of each specimen was selected for testing. A $0.7 \mathrm{~mm}$ length was measured with a $0.8 \mathrm{~mm}$ cutoff length and a 40 surface filter number selected for all the groups (based on ISO 4288-1996) [12] [15].

The abraded surfaces of indenters and crows were observed under Scanning Electron Microscopy (SEM) (Figure 2). One-way ANOVA and Tukey test ( $\mathrm{p}=$ 0.05 ) were employed for analysis of wear results.

\section{Results}

ANOVA indicated a significant difference for the steatite wear values among different groups $(\mathrm{p}<0.001)$ (Table 1$)$. Artificial enamel abraded against veneered crows $(\mathrm{BL})$ had significantly higher material loss $\left(0.217 \mathrm{~mm}^{3} \pm 0.015\right)$ than those abraded against monolithic zirconia crows, polished (PM - 0.167 $\left.\mathrm{mm}^{3} \pm 0.02\right)$ and glazed $\left(\mathrm{GM}-0.101 \mathrm{~mm}^{3} \pm 0.03\right)$. There was no significant difference between PM and GM. 


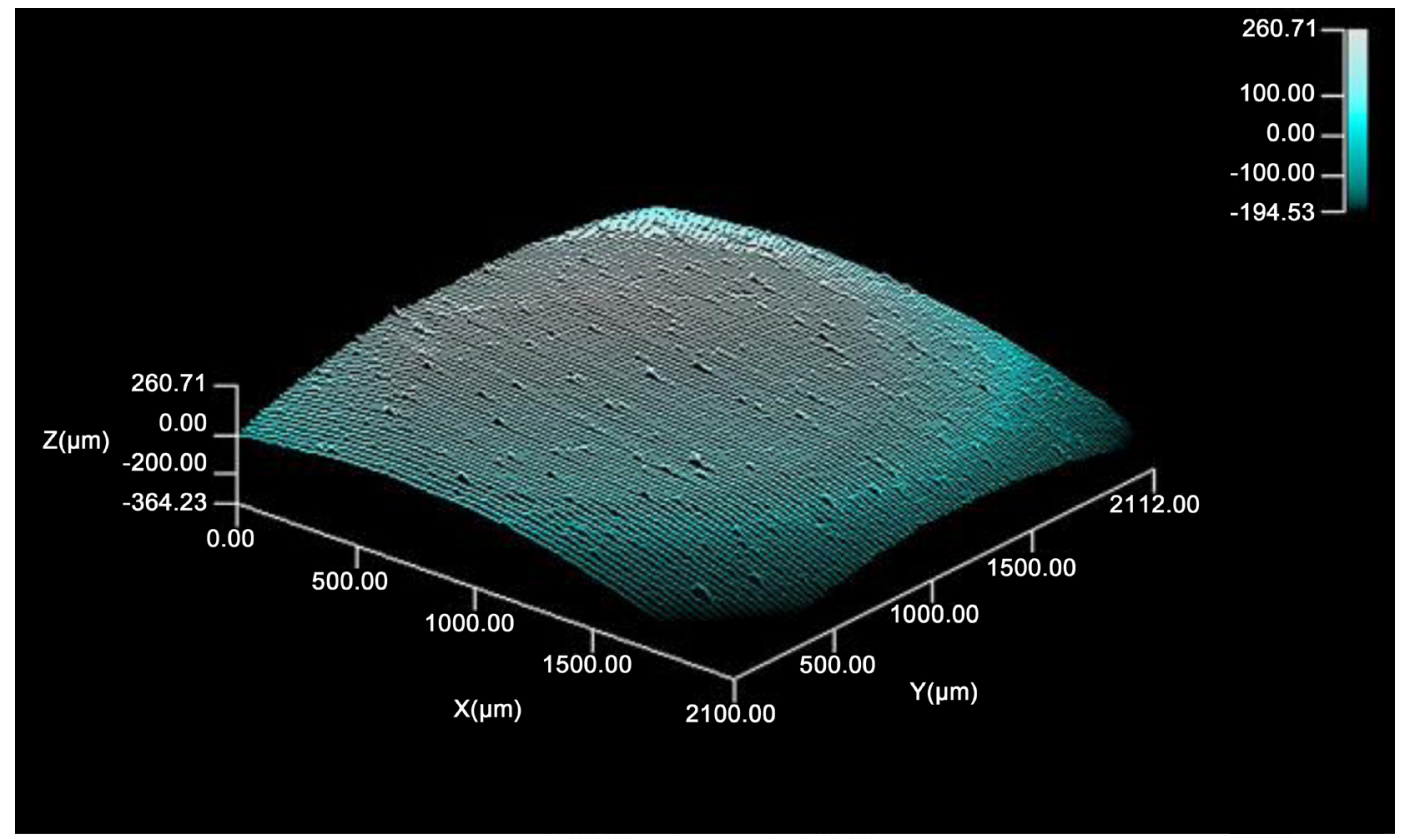

Figure 1. Digital profile of a steatite indenter abraded against PM. Volume of material loss was obtained by comparing aged indenters against the profile of an unaged sample.

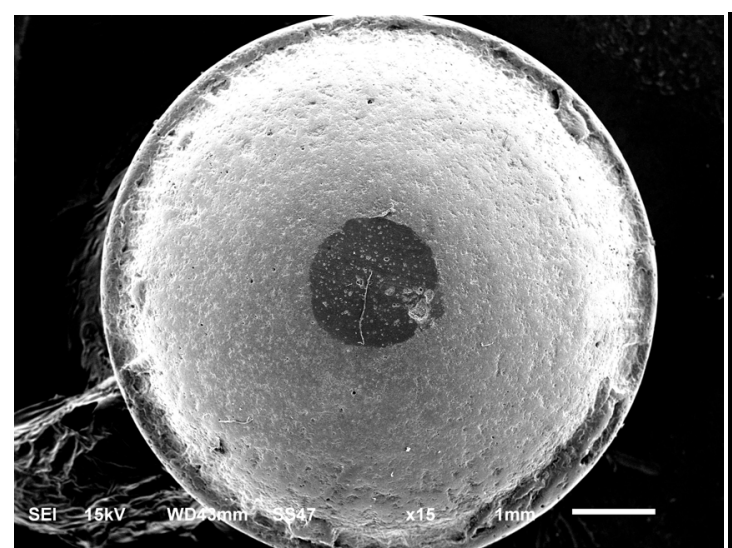

(a)

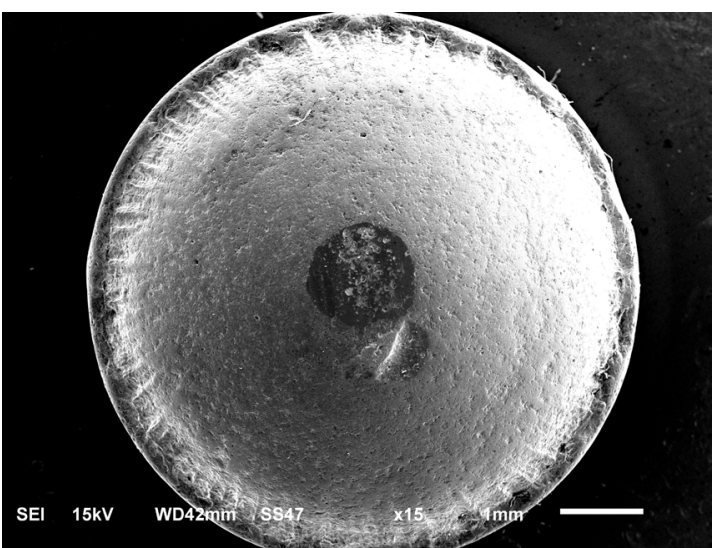

(b)

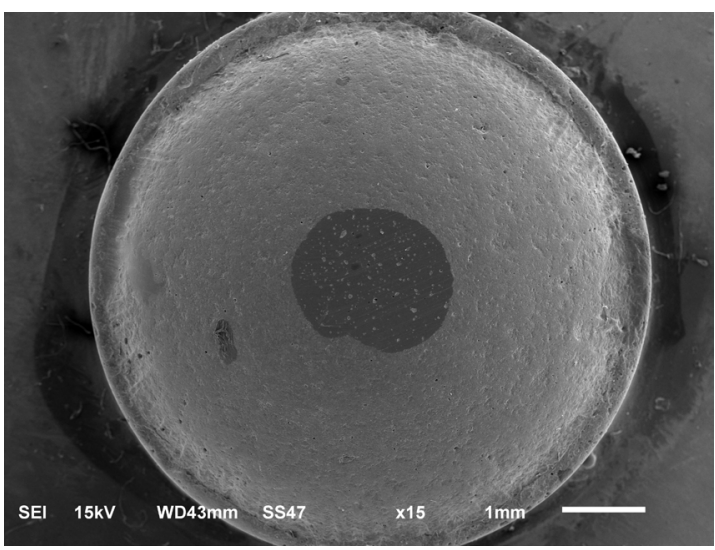

(c)

Figure 2. Overview of scanning electron micrographs of steatite antagonists against: (a) Polished monolithic (PM); (b) glazed monolithic (GM); (c) bi-layered veneered (BL) zirconia crowns. 
The occlusal surface of BL crowns presented higher roughness $(\mathrm{Ra})$ values, after aging, than PM and GM crowns (Table 2). Roughness of BL group increased after aging, and it decreased for PM and GM groups. This result was confirmed by SEM (Figure 3) showing that the worn surface of BL became roughest than the other groups after aging. Figure $3(\mathrm{c})$ shows BL worn surface revealing sharp surface irregularities on the occlusal surface. The SEM of a PM crown revealed that occlusal surface presented deep scratches (Figure 3(a)). And SEM of GM crown indicates that glaze layer was removed after aging, showing different material layers (veneer ceramic and zirconia) (Figure 3(b)).

\section{Discussion}

The wear of enamel against Y-TZP prostheses after prolonged chewing simulation is a relevant issue that needs to be carefully investigated. Artificial aging was

Table 1. Material loss $\left(\mathrm{mm}^{3}\right)$ and SD (Standard deviation) for Y-TZP-based materials with different surface finishing.

\begin{tabular}{cccc}
\hline Crown design & Material loss $\left(\mathrm{mm}^{3}\right)$ & Std. Deviation & Tukey $(\mathrm{p}=0.05)$ \\
\hline Polished monolithic (PM) & 0.167 & 0.02 & $\mathrm{a}$ \\
Glazed monolithic (GM) & 0.101 & 0.03 & $\mathrm{a}$ \\
Bi-layered veneered (BL) & 0.217 & 0.015 & $\mathrm{~b}$ \\
\hline
\end{tabular}

${ }^{\star}$ Dissimilar letters within the same column indicate groups with significant differences.

Table 2. Roughness (Ra) values for Y-TZP-based materials with different surface finishing.

\begin{tabular}{ccc}
\hline & Ra Values & Ra Values \\
\cline { 2 - 3 } Crown design & Unaged & Aged \\
\hline Polished monolithic (PM) & $0.00051 \mu \mathrm{m}$ & $0.000321 \mu \mathrm{m}$ \\
Glazed monolithic (GM) & $0.00095 \mu \mathrm{m}$ & $0.00054 \mu \mathrm{m}$ \\
Bi-layered veneered (BL) & $0.000433 \mu \mathrm{m}$ & $0.000515 \mu \mathrm{m}$ \\
\hline
\end{tabular}

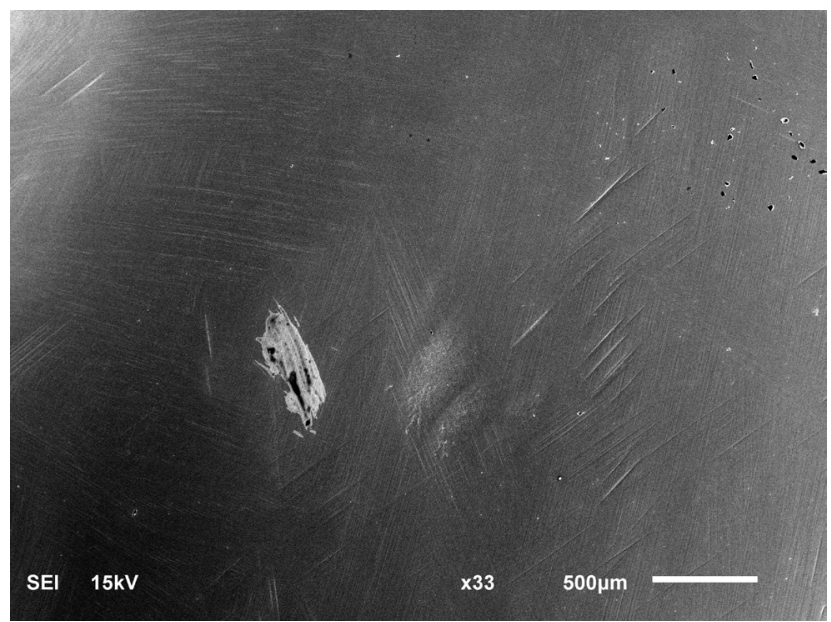

(a) 


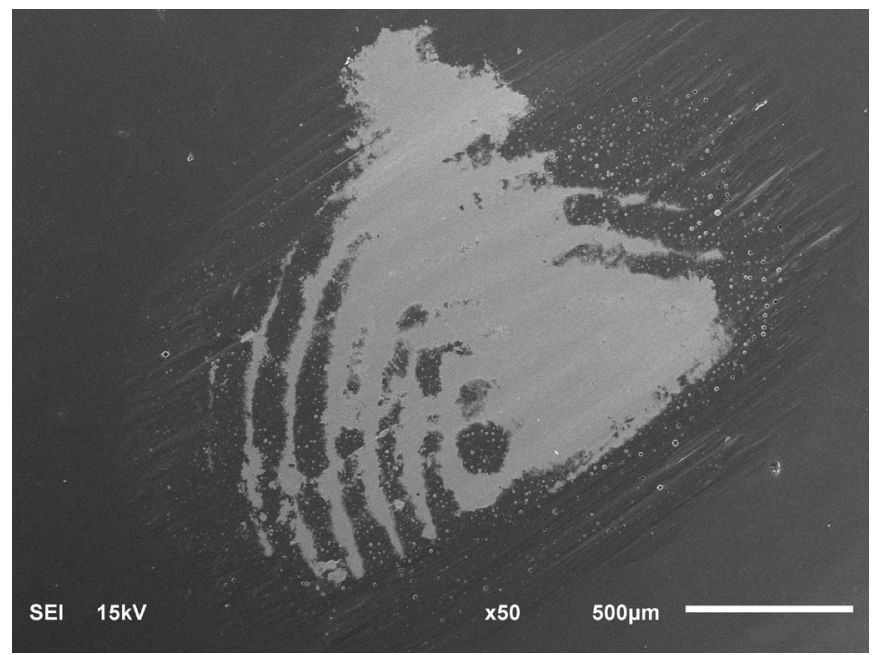

(b)

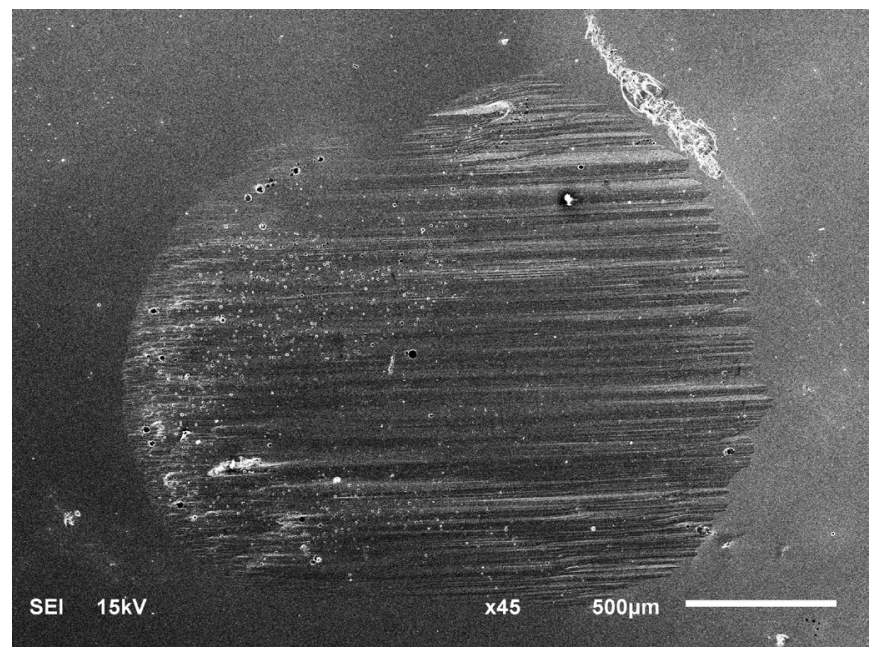

(c)

Figure 3. Overview of scanning electron micrographs of zirconia crowns after application of chewing simulation: (a) Polished monolithic (PM); (b) Glazed monolithic (GM); (c) Bi-layer veneered (BL).

performed in the present study in order to duplicate the effect of mastication between zirconia-based crowns and tooth structure by associating cyclic loading, an antagonist tooth, mouth temperature and artificial saliva. Five-years aging in the mouth were simulated by 2.5 million mechanical cycles, considering that an average adult would perform around 500,000 loading cycles/year [16]. However, wear studies can present a large variation between number of cycles and the vertical loading applied, with in vitro studies reporting the application of 5000 to 400,000 cycles [12] [14] [17] [18] [19] [20]. Indeed, a literature search revealed several studies that performed 1,200,000 cycles with $50 \mathrm{~N}$ of vertical load [8] [21] [22]. Therefore, $80 \mathrm{~N}$ load was applied for this study in order to simulate high masticatory forces. In terms of temperature, the oral environment is exposed to thermal changes according to daily food habits. This thermal variation was simulated in some in vitro studies with thermal cycles of $5^{\circ} \mathrm{C}$ to $55^{\circ} \mathrm{C}$ [17] [18] 
[21] [22] [23]. In the present study, a constant temperature of $37^{\circ} \mathrm{C}$ was applied to simulate the average human body temperature. Oral $\mathrm{pH}$ variations are also linked to the food habits and they can also play a role on the wear of enamel opposing zirconia-based crowns. A previous study reported that Y-TZP ceramics are susceptible to low temperature degradation in an acidic environment [24], but this effect was not evaluated in the present study.

All the specimens survived the artificial aging in the chewing simulator, with no visible failure/fracture. This result indicates a stable performance of zirconia-based crowns under $80 \mathrm{~N}$ load, during 5 years-simulated aging. Previous in vivo studies demonstrated a survival rate of porcelain-veneered zirconia restorations of $79 \%-100 \%$ after 5 years [6] [7], and the most frequent clinical problem was the fracture of the veneering porcelain.

The results of this study indicate significant differences in the material loss of steatite abraded against zirconia crowns with different surface materials. Therefore, the first null hypothesis was rejected. Bi-layer zirconia crowns caused significantly higher steatite wear than monolithic crowns. This result is in accordance with previous studies that showed higher antagonist's wear against veneering porcelain than full-contour zirconia [12] [13] [15] [17] [18] [19]. Many factors may have contributed to these results. The veneering porcelain is composed of a crystalline leucite phase surrounded by an amorphous glassy matrix [25], and the crystalline leucite phase can cause antagonist's wear in two ways [12]. The leucite crystals, which are more abrasive than the surrounding glass matrix, can damage the opposing enamel. Then, the partial removal of the leucite crystals by abrasion exposes the glassy matrix, which is susceptible to fracture. Thus, fractured and sharp glassy edges cause further damage by abrasive removal of the opposing tooth structure, increasing its roughness [12]. The consequences of this are twofold: the abrasive porcelain roughens up the enamel, which in turn scratches and damages the porcelain even further. In the present study, the SEM of aged BL occlusal surface (Figure 3(c)) shows a scratched porcelain veneer surface, which appears to be a consequence of the abrasion between porcelain and the roughened opposing indenter. A previous study indicated that high enamel wear caused by glass particles in the Leucite and Lithium-based ceramics could be partly explained by the formation of wear debris, which remain in the chewing site [26].

Different from veneering porcelain structure, zirconia is a polycrystalline ceramic with no glass content [25], and its crystalline microstructure along with its transformation toughening ability result in a combination of high fracture strength and hardness [27]. The high hardness values might be a reason for concern due to the possibility of wearing down the opposing dentition during masticatory function, but previous studies have concluded that there is no correlation between ceramic hardness and enamel wear [28] [29]. A good predictor of antagonist wear is actually the roughness of the substrate [15] [30]. Indeed, the theory is that the smooth zirconia surface can prevent abrasive wear of the 
opposing enamel [12] [26]. In this study, monolithic zirconia groups caused significantly less wear of the opposing artificial enamel than the veneered bilayer crowns, and it was associated with an even smoother Y-TZP surface after 2.5 million cycles. Therefore, the results of this in vitro study corroborate the concept that the roughness of a surface is more critical than the material's hardness in regard to wear of the opposing surface.

Considering the effect of aging on roughness $(\mathrm{Ra})$ values, BL specimens presented higher values after chewing simulation. Unlike, GM and PM specimens were rougher before than after chewing simulation. This result may be explained by the SEM of the glazed specimen (Figure 3(b)), which reveals that the glaze material was removed by the abrasion against the antagonist surface during chewing simulation, exposing zirconia and making the occlusal surface smoother after aging. For PM specimens, even though control samples (unaged) already presented the lowest roughness values among the groups, it seems that the chewing simulation promoted a surface smoothening effect, slightly decreasing the surface roughness even further. In accordance with this study, Janyavula et al [15] evidenced that polished monolithic zirconia specimens had lower roughness (Ra) values than bi-layer zirconia crowns. The low roughness of PM zirconia specimens after chewing simulation needs to be evaluated with caution. Humidity, loading and grain size are all contributing factors to phase transformation on zirconia surface. The PM group was the only one abrading zirconia directly against the antagonist, which means that the material was unprotected in the oral-like environment. Even though the high number of cycles was designed to simulate 5 years of aging, the frequency of the cyclic loading (approximately 2.5 $\mathrm{Hz}$ ) was much higher than the average human mastication frequency, so that the study could be accomplished within a reasonable period of time. It appears that time would also play a role in the infiltration of water through the microcracked layer of the transformed Y-TZP surface, causing further transformation and subsequent damage. More studies are needed to clarify the role of those factors on roughness and phase transformation of zirconia specimens.

Under the limitation of the present study, we demonstrated that monolithic zirconia crowns caused less wear to opposing enamel than veneering porcelain, indicating the safe use of zirconia in high load masticatory areas as opposed to bi-layer all-ceramic restorations. However, this study failed in replicating many of the challenging factors present in the oral environment, such as: $\mathrm{pH}$ variation, temperature variation and unevenness of the masticatory forces. Furthermore, the opposing natural teeth were replicated using steatite indenters, so that specimens with an identical shape could be evaluated, but the analysis of natural human teeth is highly desirable to precisely evaluate the outcomes of the mastication loads against Y-TZP crowns. Therefore, future studies concerning temperature and $\mathrm{pH}$ variations should be developed. Although expensive and time-consuming, clinical trials are an unquestionable valuable tool to better evaluate the clinical performance of monolithic zirconia restorations. 


\section{Conclusion}

The results of this study indicate that the effect of veneering porcelain on artificial enamel wear is more pronounced than the Y-TZP surface itself. Surface finishing of monolithic Y-TZP crowns does not have an effect on the wear of the antagonist artificial enamel.

\section{Acknowledgements}

The authors thank CAPES for the first author's PhD sandwich scholarship (Process BEX 17246/12-1). The materials employed were kindly donated by 3M-ESPE Canada, and crowns manufacturing were made by Rotsaert Dental Laboratory. Additional laboratorial expenses were supported by University of Toronto Start-up fund.

\section{Conflict of Interests}

The authors declare that there is no conflict of interests regarding the publication of this paper.

\section{References}

[1] Kwon, T.K., Pak, H.S., Yang, J.H., Han, J.S., Lee, J.B., Kim, S.H. and Yeo, I.S. (2013) Comparative Fracture Strength Analysis of Lava and Digident CAD/CAM Zirconia Ceramic Crowns. Journal of Advanced Prosthodontics, 5, 92-97. https://doi.org/10.4047/jap.2013.5.2.92

[2] Zhang, F., Inokoshi, M., Batuk, M., Hadermann, J., Naert, I., Van Meerbeek, B. and Vleugels, J. (2016) Strength, Toughness and Aging Stability of Highly-Translucent Y-TZP Ceramics for Dental Restorations. Dental Materials, 32, 327-337. https://doi.org/10.1016/j.dental.2016.09.025

[3] Flinn, B.D., deGroot, D.A., Mancl, L.A. and Raigrodski, A.J. (2012) Accelerated Aging Characteristics of Three Yttria-Stabilized Tetragonal Zirconia Polycrystalline Dental Materials. Journal of Prosthetic Dentistry, 108, 223-230. https://doi.org/10.1016/S0022-3913(12)60166-8

[4] Miyazaki, T., Nakamura, T., Matsumura, H., Ban, S. and Kobayashi, T. (2013) Current Status of Zirconia Restoration. Journal of Prosthodontic Research, 57, 236-261. https://doi.org/10.1016/j.jpor.2013.09.001

[5] Lin, W.S., Ercoli, C., Feng, C. and Morton, D. (2012) The Effect of Core Material, Veneering Porcelain, and Fabrication Technique on the Biaxial Flexural Strength and Weibull Analysis of Selected Dental Ceramics. Journal of Prosthodontics, 21, 353-362. https://doi.org/10.1111/j.1532-849X.2012.00845.x

[6] Sorrentino, R., De Simone, G., Tetè, S., Russo, S. and Zarone, F. (2012) Five-Year Prospective Clinical Study of Posterior Three-Unit Zirconia-Based Fixed Dental Prostheses. Clinical Oral Investigations, 16, 977-985. https://doi.org/10.1007/s00784-011-0575-2

[7] Vigolo, P. and Mutinelli, S. (2012) Evaluation of Zirconium-Oxide-Based Ceramic Single-Unit Posterior Fixed Dental Prostheses (FDPs) Generated with Two CAD/CAM Systems Compared to Porcelain-Fused-To-Metal Single-Unit Posterior FDPs: A 5-Year Clinical Prospective study. Journal of Prosthodontics, 21, 265-269. https://doi.org/10.1111/j.1532-849X.2011.00825.x 
[8] Stawarczyk, B., Ozcan, M., Roos, M., Trottmann, A., Sailer, I. and Hämmerle, C.H. (2011) Load-Bearing Capacity and Failure Types of Anterior Zirconia Crowns Veneered with Overpressing and Layering Techniques. Dental Materials, 27, 1045-1053. https://doi.org/10.1016/j.dental.2011.07.006

[9] Zhang, Y., Lee, J.J., Srikanth, R. and Lawn, B.R. (2013) Edge Chipping and Flexural Resistance of Monolithic Ceramics. Dental Materials, 29, 1201-1208. https://doi.org/10.1016/j.dental.2013.09.004

[10] Lameira, D.P., Buarque e Silva, W.A., Andrade e Silva, F. and De Souza, G.M. (2015) Fracture Strength of Aged Monolithic and Bilayer Zirconia-Based Crowns. BioMed Research International, 2015, 418641. https://doi.org/10.1155/2015/418641

[11] Chevalier, J., Loh, J., Gremillard, L., Meille, S. and Adolfson, E. (2011) Low-Temperature Degradation in Zirconia with a Porous Surface. Acta Biomaterialia, 7, 2986-2993. https://doi.org/10.1016/j.actbio.2011.03.006

[12] Burgess, J.O., Janyavula, S., Lawson, N.C., Lucas, T.J. and Cakir, D. (2014) Enamel Wear Opposing Polished and Aged Zirconia. Operative Dentistry, 39, 189-194. https://doi.org/10.2341/12-345-L

[13] Preis, V., Behr, M., Kolbeck, C., Hahnel, S., Handel, G. and Rosentritt, M. (2011) Wear Performance of Substructure Ceramics and Veneering Porcelains. Dental Materials, 27, 796-804. https://doi.org/10.1016/j.dental.2011.04.001

[14] Ablal, M.A., Kaur, J.S., Cooper, L., Jarad, F.D., Milosevic, A., Higham, S.M. and Preston, A.J. (2009) The Erosive Potential of Some Alcopops Using Bovine Enamel: an In Vitro Study. Journal of Dentistry, 37, 835-839. https://doi.org/10.1016/j.jdent.2009.06.016

[15] Janyavula, S., Lawson, N., Cakir, D., Beck, P., Ramp, L.C. and Burgess, J.O. (2013) The Wear of Polished and Glazed Zirconia against Enamel. Journal of Prosthetic Dentistry, 109, 22-29. https://doi.org/10.1016/S0022-3913(13)60005-0

[16] Teixeira, E.C., Piascik, J.R., Stoner, B.R. and Thompson, J.Y. (2007) Dynamic Fatigue and Strength Characterization of Three Ceramic Materials. Journal of Materials Science: Materials in Medicine, 18, 1219-1224. https://doi.org/10.1007/s10856-007-0131-4

[17] Jung, Y.S., Lee, J.W., Choi, Y.J., Ahn, J.S., Shin, S.W. and Huh, J.B. (2010) A Study on the In-Vitro Wear of the Natural Tooth Structure by Opposing Zirconia or Dental Porcelain. Journal of Advanced Prosthodontics, 2, 111-115. https://doi.org/10.4047/jap.2010.2.3.111

[18] Kim, M.J., Oh, S.H., Kim, J.H., Ju, S.W., Seo, D.G., Jun, S.H., Ahn, J.S. and Ryu, J.J. (2012) Wear Evaluation of the Human Enamel Opposing Different Y-TZP Dental Ceramics and Other Porcelains. Journal of Dentistry, 40, 979-988. https://doi.org/10.1016/j.jdent.2012.08.004

[19] Kontos, L., Schille, C., Schweizer, E. and Geis-Gerstorfer, J. (2013) Influence of Surface Treatment on the Wear of Solid Zirconia. Acta Odontologica Scandinavica, 71, 482-487. https://doi.org/10.3109/00016357.2012.696690

[20] Luangruangrong, P., Cook, N.B., Sabrah, A.H., Hara, A.T. and Bottino, M.C. (2014) Influence of Full-Contour Zirconia Surface Roughness on Wear of Glass-Ceramics. Journal of Prosthodontics, 23, 198-205. https://doi.org/10.1111/jopr.12088

[21] Preis, V., Behr, M., Hahnel, S., Handel, G. and Rosentritt, M. (2012) In Vitro Failure and Fracture Resistance of Veneered and Full-Contour Zirconia Restorations. Journal of Dentistry, 40, 921-928. https://doi.org/10.1016/j.jdent.2012.07.010

[22] Preis, V., Behr, M., Handel, G., Schneider-Feyrer, S., Hahnel, S. and Rosentritt, M. 
(2012) Wear Performance of Dental Ceramics after Grinding and Polishing Treatments. Journal of the Mechanical Behavior of Biomedical Materials, 10, 13-22. https://doi.org/10.1016/j.jmbbm.2012.03.002

[23] Stawarczyk, B., Özcan, M., Schmutz, F., Trottmann, A., Roos, M. and Hämmerle, C.H. (2013) Two-Body Wear of Monolithic, Veneered and Glazed Zirconia and Their Corresponding Enamel Antagonists. Acta Odontologica Scandinavica, 71, 102-112. https://doi.org/10.3109/00016357.2011.654248

[24] Egilmez, F., Ergun, G., Cekic-Nagas, I., Vallittu, P.K. and Lassila, L.V. (2014) Factors Affecting the Mechanical Behavior of Y-TZP. Journal of the Mechanical Behavior of Biomedical Materials, 37, 78-87. https://doi.org/10.1016/j.jmbbm.2014.05.013

[25] Kelly, J.R. and Benetti, P. (2011) Ceramic Materials in Dentistry: Historical Evolution and Current Practice. Australian Dental Journal, 56, 84-96. https://doi.org/10.1111/j.1834-7819.2010.01299.x

[26] Choi, J.W., Bae, I.H., Noh, T.H., Ju, S.W., Lee, T.K., Ahn, J.S., Jeong, T.S. and Huh, J.B. (2016) Wear of Primary Teeth Caused by Opposed All-Ceramic or Stainless Steel Crowns. Journal of Advanced Prosthodontics, 8, 43-52.

https://doi.org/10.4047/jap.2016.8.1.43

[27] Garcia Fonseca, R., de Oliveira Abi-Rached, F., dos Santos Nunes Reis, J.M., Rambaldi, E. and Baldissara, P. (2013) Effect of Particle Size on the Flexural Strength and Phase Transformation of an Airborne-Particle Abraded Yttria-Stabilized Tetragonal Zirconia Polycrystal Ceramic. Journal of Prosthetic Dentistry, 110, 510-514. https://doi.org/10.1016/j.prosdent.2013.07.007

[28] Dahl, B.L. and Oilo, G. (1994) In Vivo Wear Ranking of Some Restorative Materials. Quintessence International, 25, 561-565.

[29] Seghi, R.R., Rosenstiel, S.F. and Bauer, P. (1991) Abrasion of Human Enamel by Different Dental Ceramics in Vitro. Journal of Dental Research, 70, 221-225. https://doi.org/10.1177/00220345910700031301

[30] Ghazal, M. and Kern, M. (2009) The Influence of Antagonistic Surface Roughness on the Wear of Human Enamel and Nanofilled Composite Resin Artificial Teeth. Journal of Prosthetic Dentistry, 101, 342-349. https://doi.org/10.1016/S0022-3913(09)60068-8 